\title{
Indoor Exposure to Mould and Dampness in Infancy and Its Association to Persistent Atopic Dermatitis in School Age: Results from the Greek ISAAC II Study
}

\author{
Papadopoulou Athina, ${ }^{12}$, Mermiri Despina², Xatziagorou Elpida3 ${ }^{3}$ Lambidi Stavroula1, \\ Cratziou Christina ${ }^{4}$, Tsanakas Ioannis ${ }^{3}$ \\ ${ }^{1}$ Allergy Pediatric Unit, KAT General Hospital, Athens, Greece \\ ${ }^{2}$ Allergology and Respiratory Unit, Penteli's Children Hospital, Athens, Greece \\ ${ }^{3}$ 3rd Pediatric Department, Aristoleleio University, Thessaloniki, Greece \\ ${ }^{4}$ Evgenidio Hospital, School of Medicine, University of Athens, Athens, Greece \\ Email: *athinapap@yahoo.com
}

Received 22 January 2016; accepted 7 March 2016; published 11 March 2016

Copyright (C) 2016 by authors and Scientific Research Publishing Inc.

This work is licensed under the Creative Commons Attribution International License (CC BY). http://creativecommons.org/licenses/by/4.0/

c) (7) Open Access

\section{Abstract}

Introduction: The presence of mould as a source of perennial allergens and bacteria products has been related to the appearance of respiratory symptoms in several studies. Yet, its role in eczema has not been elucidated. The aim of this study was to investigate the association between exposure to indoor visible molds/dampness and the manifestation of eczema in children. Methods: The study is part of the Greek contribution to ISAAC II that includes 2023 students of randomly selected public primary schools in Athens and Thessaloniki, aged 9 - 10 years old. The children repre- sented a general population sample and were evaluated according to ISAAC II questionnaire, validated for Greek language. Additionally, skin prick tests to aero-allergens were performed and children were examined for active skin lesions. Results: $13 \%$ had suffered from eczema in the past, $9 \%$ had current and $2 \%$ had atopic eczema (positive at least one skin prick test). Out of the children examined, half reported that eczema first appeared after the age of five years old whereas $70 \%$ mentioned persistence of eczema. Dampness was reported in $10.8 \%$ and visible mould in $6.4 \%$ of all cases during infancy, while continued exposure until the age of 10 years old was reported in $\mathbf{3 8 \%}$ and $33 \%$ out of them respectively. $10.8 \%$ of the sensitized children were positive to house dust mites and Alternaria, however, sensitization was not related to indoor exposure. In logistic regression analysis evaluating 20 environmental risk factors, a significant association was noted between the presence of indoor visible mold and dampness in infancy, and the presence of current

${ }^{*}$ Corresponding author.

How to cite this paper: Athina, P., Despina, M., Elpida, X., Stavroula, L., Christina, C. and Ioannis, T. (2016) Indoor Exposure to Mould and Dampness in Infancy and Its Association to Persistent Atopic Dermatitis in School Age: Results from the Greek ISAAC II Study. Open Journal of Pediatrics, 6, 75-81. http://dx.doi.org/10.4236/ojped.2016.61013 
eczema OR 1, $89(95 \%$ CI 1.18 - 3.03). This association remained significant irrespective of the family history of eczema and sensitization. Conclusions: Frequently eczema first appears at early school age. The presence of visible mold and dampness at home during infancy appears to be an initial enhancing risk factor for the development but also for the persistence of the disease throughout school age.

\section{Keywords}

\section{Persistent Atopic Dermatitis, Mould, Dampness, ISAAC II, Children}

\section{Introduction}

The discovery of the filaggrin skin barrier gene mutations and its relationship to the development and severity of atopic dermatitis $(\mathrm{AD})$ has highlighted the interaction between genes and environment in such a multifactorial disease. New environmental factors that have an impact on skin barrier function are constantly being evaluated [1]. Antenatal and postnatal factors such as caesarian section, broad-spectrum antibiotic use, western diets, obesity, cat ownership, changes in gut flora diversity are major culprits for changes in innate and adaptive immunity leading to AD phenotypes. It is well known that children spend most of their time in an indoor environment (home or school) exposed to many allergenic (i.e. moulds) and non-allergenic (i.e. building dampness) stimuli collectively referred to as "indoor pollution".

Indoor dampness and mould constitutes a complex mixture consisting of mites and pets' epithelia, bacterial products, fungi components (mainly Aspergillus spp., Penicillium spp., Cladosporium cladosporioides and Alternaria spp.) and various bio contaminants (pesticides, polycylic aromatic hydrocarbons, polychlorinated biphenyls, alcohols and ketones) [2]. 88\% of fungi produce active metabolites which inadvertently affect ciliary movement [3]. That is why, early enough, a decade ago, dampness and mould were associated with respiratory infections, asthmatic symptomatology and allergy sensitization in adults and children [4]-[8]. Interestingly, while the association between exposure and wheezing has been reported very early in the first 15 months of life, its role in eczema has not been elucidated [9]. A study at 2010 first reported that the most important risk factors for atopic eczema were family and personal history of other atopic diseases and the presence of fungi at home [10]. Moreover, Isaac phase II study, three years later, concluded that there was a consistent association of dampness with respiratory symptoms and eczema, in both affluent and non-affluent countries, among both atopic and non-atopic children. It also concluded that house dust mites exposure and sensitization might have a contribution, but the link seemed to be related principally to non-atopic mechanisms [11].

Infancy is considered as a window through which environmental factors can play either a beneficial or hazardous role. The aim of this study was to evaluate the presence of dampness and moulds at home since infancy and its relation to $\mathrm{AD}$ at school age.

\section{Methods}

2023 Greek randomly selected schoolchildren, 1000 from Athens, 1023 from Thessaloniki, aged 9 - 10 years old (47.9\% boys) participated in the ISAAC-II survey. They all answered the standardized and validated, selfadministered ISAAC-II questionnaire, tested with skin prick testing (SPT) to seven common aeroallergen produced by ALK (Horsholm, Dermark/mixed grass pollen, mixed tree pollen and olive tree pollen, Dermatophagoides Pteronyssinus (DP), Dermatophagoides Farinae (DF), Alternaria Tenuis, cat dander) and examined for flexural dermatitis.The presence of lifetime itching relapsing rash was defined as lifetime AD whereas the presence of this rash in the last 12 month period was defined as current AD. The coexistence of any sensitization conferred the eczema an atopic characterization. Data concerning the age at which AD started, the severity of the disease (sleep disturbance) and parental history of eczema were also collected. From the overall questionnaire, factors acting during infancy (before the age of 2 years old) were analysed in relation to AD such as breast feeding, mother smoking habits, visible mould and dampness in houses, contact with pets and farm animals, attending nursery school, bedroom sharing with siblings, house heating habits, use of air conditioners, fitted carpets placement and the type of pillow and quilts preferred. Parents' education status and gestational age were 
also recorded. Multi-validated in three step wise models' regression analysis of 20 environmental factors, that showed significance in the univariate analysis, was used to evaluate the association with atopic dermatitis. The results are presented as odd ratios (OR) and their corresponding 95\% confidence intervals. Hosmer-Lemeshow statistic was calculated in order to assess model's goodness of fit. Colinearity between factors entered in each model was evaluated using the correlation coefficients of the estimates. SPSS 20.0 statistical programme (SPSS Hellas, Athens, Greece) was used to analyse the data.

\section{Results}

In Athens compared to Thessaloniki, children more often breast fed, lived in houses with central heating, aircondition and fitted carpets and used quilts for bedding (Table 1). Despite of that, in Athens damp spots and mould were often more visible. On the other hand, in Thessaloniki parents had a significantly higher education level, children more often owned pets and used blankets for bedding. Mother smoking habits and parental history of eczema did not differ between the two cities. Dampness was reported in $10.8 \%$ and visible mould in $6.4 \%$ of all cases during infancy, while continued exposure until the age of 10 years old was reported in $38 \%$ and 33\% out of them respectively. The prevalence of lifetime and current AD was $13 \%$ and $9.1 \%$ respectively and no significant difference was detected between the two cities (Table 2). AD started in half of the children after the age of 5 years and was mild to moderate in the majority of the cases. 70\% of the children both in Thessaloniki and Athens with lifetime eczema reported current eczema at the age of 10 years old. Sensitization was significantly higher in Thessaloniki than in Athens and was found in $22 \%$ of the cases with history of current AD. Moreover, $10.8 \%$ of them were sensitized to perennial aeroallergen (DP, DF, Alternaria) and $7.3 \%$ to cat dander. However, sensitization was not related to indoor exposure ( $p>0.05)$. During multi-validated analysis, the presence of damp spots and visible mould in infancy was associated with current atopic dermatitis, after adjusting for various other environmental and lifestyle factors (Table 3). Parental history of eczema was a constant

Table 1. Social and environmental characteristics in infancy of the children that participated in the study.

\begin{tabular}{|c|c|c|c|c|}
\hline & $\begin{array}{c}\text { Athens } \\
\mathrm{n}=1000 \\
\%\end{array}$ & $\begin{array}{c}\text { Thessaloniki } \\
\mathrm{n}=1023 \\
\%\end{array}$ & $p$ & $\begin{array}{c}\text { All } \\
\mathrm{n}=2023 \\
\%\end{array}$ \\
\hline Sex (male) & 46.1 & 49.7 & 0.11 & 47.9 \\
\hline Preterm infant & 15.5 & 16.3 & 0.69 & 15.9 \\
\hline Both parents with academic education & 22.8 & 57.0 & $<0.01$ & 39.9 \\
\hline Mother smoking habits & 32.6 & 29.8 & 0.19 & 31.2 \\
\hline Maternal history of eczema & 9.7 & 10.2 & 0.76 & 9.9 \\
\hline Paternal history of eczema & 7.3 & 6.6 & 0.54 & 6.9 \\
\hline Breast feeding & 78.6 & 74.7 & 0.03 & 76.6 \\
\hline Attending nursery school before the age of $2 \mathrm{y}$ & 13 & 10.8 & 0.13 & 11.9 \\
\hline Bedroom sharing & 78.4 & 78.1 & 0.91 & 78.3 \\
\hline Pets ownership & 8.3 & 12.2 & 0.04 & 10.3 \\
\hline Farm animals exposure & 1.6 & 2.4 & 0.20 & 2 \\
\hline Air-condition in the house & 11.3 & 7.2 & $<0.01$ & 9.2 \\
\hline Central heating in the house & 76.6 & 40.4 & $<0.01$ & 58.2 \\
\hline Dampness in the house & 13.2 & 8.4 & $<0.01$ & 10.8 \\
\hline Visible moulds in the house & 7.8 & 5 & $<0.01$ & 6.4 \\
\hline Fitted carpets in child bedroom & 57.9 & 29.3 & $<0.01$ & 43.5 \\
\hline Use of foam pillows & 14.1 & 11.9 & 0.14 & 13 \\
\hline Use of synthetic pillows & 14.2 & 14 & 0.89 & 14.1 \\
\hline Use of feather pillows & 25.8 & 29.2 & 0.08 & 27.5 \\
\hline Use of synthetic quilts & 22.7 & 17.1 & 0.02 & 19.9 \\
\hline Use of feather quilts & 13.5 & 9 & 0.02 & 11.2 \\
\hline Use of blankets & 68.2 & 75.8 & $<0.01$ & 72 \\
\hline
\end{tabular}

P-values derived from Pearson's chi square test. 
Table 2. Prevalence of eczema and sensitization in 9 - 10-year-old children that participated in the study.

\begin{tabular}{|c|c|c|c|c|}
\hline & $\begin{array}{c}\text { Athens } \\
\mathrm{n}=1000 \\
\%\end{array}$ & $\begin{array}{c}\text { Thessaloniki } \\
\mathrm{n}=1023 \\
\%\end{array}$ & $p$ & $\begin{array}{c}\text { All } \\
\mathrm{n}=2023 \\
\%\end{array}$ \\
\hline \multicolumn{5}{|l|}{ Eczema last 12 months } \\
\hline current eczema, & 10.1 & 8.2 & 0.16 & 9.1 \\
\hline flexural dermatitis, & 1.3 & 1.4 & 0.89 & 1.3 \\
\hline atopic eczema, & 2.1 & 1.9 & 0.58 & 2.0 \\
\hline sleep problems > 1/week, & 1.4 & 1.8 & 0.41 & 1.6 \\
\hline Lifetime eczema & 14.4 & 11.7 & 0.07 & 13 \\
\hline *started $<2$ y old & 25.6 & 15.6 & & 20.8 \\
\hline 2 - 4 y old & 28.2 & 26.6 & 0.11 & 27.4 \\
\hline >5y old & 46.2 & 57.8 & & 51.8 \\
\hline \multicolumn{5}{|l|}{ Skin Prick Test } \\
\hline At least one, \% & 16.0 & 25.2 & $<0.001$ & 20.7 \\
\hline Pollen sensitization, \% & 14.7 & 17.0 & 0.15 & 10.2 \\
\hline Perennial sensitization, \% & 4.1 & 17.3 & $<0.001$ & 10.8 \\
\hline Cat sensitization, \% & 5.8 & 8.7 & 0.01 & 7.3 \\
\hline
\end{tabular}

Results are presented as percentages. P-values retrieved from Pearson's chi square test. " among the cases with lifetime eczema.

Table 3. Results from multiple logistic regression models that evaluated current atopic dermatitis prevalence in 9 - 10-yearold children from the two major Greek cities, Athens and Thessaloniki.

\begin{tabular}{|c|c|c|c|c|c|c|}
\hline & \multicolumn{2}{|c|}{ Model 1} & \multicolumn{2}{|c|}{ Model 2} & \multicolumn{2}{|c|}{ Model 3} \\
\hline & OR & $95 \% \mathrm{CI}$ & OR & $95 \% \mathrm{CI}$ & OR & $95 \% \mathrm{CI}$ \\
\hline Boys vs. girls & 1.28 & $0.91-1.81$ & 1.28 & $0.91-1.81$ & 1.29 & $0.91-1.82$ \\
\hline Athens vs. Thessaloniki & 0.92 & $0.63-1.34$ & 0.92 & $0.63-1.34$ & 1.04 & $0.68-1.58$ \\
\hline Parents with academic education & 0.79 & $0.54-1.15$ & 0.79 & $0.54-1.16$ & 0.79 & $0.53-1.16$ \\
\hline Preterm & 0.94 & $0.58-1.52$ & 0.94 & $0.58-1.52$ & 0.95 & $0.58-1.55$ \\
\hline Maternal history of eczema & 1.74 & $1.08-2.79^{*}$ & 1.84 & $1.14-2.97^{*}$ & 1.77 & $1.09-2.88^{*}$ \\
\hline Paternal history of eczema & 2.17 & $1.30-3.62^{*}$ & 2.16 & $1.29-3.61^{*}$ & 2.24 & $1.33-3.75^{*}$ \\
\hline Sensitization to perennial & 0.97 & $0.54-1.77$ & 0.99 & $.54-1.80$ & 0.96 & $0.52-1.75$ \\
\hline Dampness and visible mould & 1.9 & $1.20-3.00^{*}$ & 1.87 & $1.18-2.98^{*}$ & 1.89 & $1.18-3.03^{*}$ \\
\hline Breast feeding & & & 1.04 & $0.69-1.57$ & 1.06 & $0.70-1.60$ \\
\hline Attending nursery school & & & 1.10 & $0.67-1.82$ & 1.08 & $0.65-1.79$ \\
\hline Mother smoking habits & & & 1.12 & $0.78-1.61$ & 1.10 & $0.76-1.58$ \\
\hline Bedroom sharing & & & 0.85 & $0.56-1.28$ & 0.86 & $0.57-1.30$ \\
\hline Pets in house & & & 1.21 & $0.70-2.08$ & 1.27 & $0.73-2.20$ \\
\hline Contact with farm animals & & & 0.29 & $0.03-2.19$ & 0.32 & $0.04-2.42$ \\
\hline Use of air condition & & & & & 1.27 & $0.72-2.23$ \\
\hline Central heating & & & & & 1.09 & $0.74-1.59$ \\
\hline Use fitted carpets in bedrooms & & & & & 1.18 & $0.82-1.69$ \\
\hline Use foam pillows & & & & & 1.15 & $0.69-1.94$ \\
\hline Use synthetic fiber pillows & & & & & 0.80 & $0.45-1.41$ \\
\hline Use feather pillows & & & & & 1.00 & $0.65-1.54$ \\
\hline Use synthetic quilts for bedding & & & & & 0.79 & $0.48-1.28$ \\
\hline Use feather quilts for bedding & & & & & 0.56 & $0.28-1.09$ \\
\hline Use blankets for bedding & & & & & 0.50 & $0.32-0.78^{*}$ \\
\hline
\end{tabular}

OR = odds ratio, 95\%CI = 95\% confidence interval. ${ }^{*} \mathrm{p}<0.05$ 
factor strongly associated with atopic dermatitis. Sensitization to perennial aeroallergens and area of residence showed no significance. The presence of damp spots and visible mould in multivariable analysis were not associated with lifetime AD (Table 4).

\section{Discussion}

Two main results emerged from this study: 1) AD frequently, appeared for the first time at an early school age and not during infancy. In contrast to our results where $50 \%$ of the cases experienced eczema after the age of 5 years, a recent review article reported that $95 \%$ of children suffer from eczema in the preschool age [12]. 2) The presence of visible mould and dampness at home during infancy appears to be an initial triggering risk factor for the development as well as for the persistence of atopic dermatitis throughout school age, independently of sensitization. It has been reported that half of the cases outgrow atopic dermatitis in preschool age and that another $1 / 4$ in early adolescence, while only $25 \%$ continue to have eczema into adulthood or experience relapse after a symptom-free period [12] [13]. However, the results of our study, showed that $7 / 10$ of those who had preschool $\mathrm{AD}$ continued to have active lesions at the age of 10 years and this seems to be strongly related to the presence of indoor visible mould and dampness early on in infancy. This association was attributed to non IgE mechanisms as sensitization to perennial aeroallergens was not significant. Studies of Batlles Garrido and Weinmayr in agreement with our results, confirmed this association, highlighting the key role of exposure during infancy.

$\mathrm{AD}$ is the prototype of mixed (IgE and non IgE) allergic disease. High levels of total IgE as well as specific IgE to environmental and food allergens are frequently encountered in extrinsic or allergic AD. As far as food allergens are concerned, about $30 \%$ of all children with atopic dermatitis are sensitized but, clinical relevance

Table 4. Results from multiple logistic regression models that evaluated lifetime atopic dermatitis prevalence in 9 - 10-yearold children from the two major Greek cities, Athens and Thessaloniki.

\begin{tabular}{|c|c|c|c|c|c|c|}
\hline & \multicolumn{2}{|c|}{ Model 1} & \multicolumn{2}{|c|}{ Model 2} & \multicolumn{2}{|c|}{ Model 3} \\
\hline & OR & $95 \% \mathrm{CI}$ & OR & $95 \% \mathrm{CI}$ & OR & $95 \% \mathrm{CI}$ \\
\hline Boys vs. girls & 1.33 & $1.00-1.17$ & 1.32 & $0.98-1.76$ & 1.31 & $0.97-1.75$ \\
\hline Athens vs. Thessaloniki & 0.86 & $0.63-1.78$ & 0.85 & $0.61-1.16$ & 0.99 & $0.70-1.42$ \\
\hline Parents with academic education & 0.86 & $0.63-1.18$ & 0.88 & $0.63-1.21$ & 0.89 & $0.64-1.23$ \\
\hline Preterm & 0.91 & $0.61-1.37$ & 0.89 & $0.59-1.35$ & 0.90 & $0.59-1.36$ \\
\hline Maternal history of eczema & 2.03 & $1.56-3.40^{*}$ & 2.40 & $1.62-3.56^{*}$ & 2.26 & $1.51-3.37^{*}$ \\
\hline Paternal history of eczema & 2.36 & $1.52-3.66^{*}$ & 2.36 & $1.52-3.68^{*}$ & 2.41 & $1.54-3.77^{*}$ \\
\hline Sensitization to perennial & 0.82 & $0.48-1.39$ & 0.85 & $0.50-1.45$ & 0.82 & $0.48-1.41$ \\
\hline Dampness and visible mould & 1.40 & $0.92-2.14$ & 1.35 & $0.88-2.08$ & 1.34 & $0.87-2.07$ \\
\hline Breast feeding & & & 1.07 & $0.75-1.52$ & 1.11 & $0.78-1.58$ \\
\hline Attending nursery school & & & 1.10 & $0.72-1.69$ & 1.08 & $0.70-1.66$ \\
\hline Mother smoking habits & & & 1.31 & $0.97-1.77$ & 1.28 & $0.94-1.74$ \\
\hline Sharing bedroom & & & 0.89 & $0.63-1.26$ & 0.88 & $0.62-1.26$ \\
\hline Pets in house & & & 1.45 & $0.93-2.26$ & 1.51 & $0.96-2.37$ \\
\hline Contact with farm animals & & & 0.54 & $0.15-1.87$ & 0.57 & $0.16-1.98$ \\
\hline Use of air condition & & & & & 0.89 & $0.52-1.50$ \\
\hline Central heating & & & & & 1.17 & $0.84-1.62$ \\
\hline Use fitted carpets in bedrooms & & & & & 1.29 & $0.95-1.76$ \\
\hline Use foam pillows & & & & & 1.35 & $0.89-2.05$ \\
\hline Use synthetic fiber pillows & & & & & 0.65 & $0.39-1.06$ \\
\hline Use feather pillows & & & & & 0.93 & $0.65-1.35$ \\
\hline Use synthetic quilts for bedding & & & & & 1.04 & $0.70-1.55$ \\
\hline Use feather quilts for bedding & & & & & 0.61 & $0.34-1.08$ \\
\hline Use blankets for bedding & & & & & 0.59 & $0.41-0.86^{*}$ \\
\hline
\end{tabular}


was noted only in moderate/severe AD cases. Infantile egg white sensitization is considered a risk factor for the persistence of AD later on in life [13] [14]. On the other hand, environmental factors have long been a contested issue in both dermatology and allergy/immunology as clear cut association with $\mathrm{AD}$ has not been found. In respect to house dust mites neither skin prick nor epicutaneous tests have proven helpful [15]. Filaggrin gene mutations play a pivotal role in the pathogenesis of $\mathrm{AD}$ affecting the integrity of corny layers of the epidermis. This favours the penetrance of environmental allergens through the skin such as indoor pollutants (mites, pet dander and fungi components). The loss of barrier function is further aggravated by the proteolytic activity of the major allergen Der p 1 (HDM) which mounts a late T-cell mediated reaction stimulating adaptive and innate immunity [16] [17]. Skin barrier defects and pathological immune response represent a chicken and egg dilemma in AD. Allergens that have penetrated defective skin barriers induce inflammation, while inflammation itself can alter skin barrier integrity (inside-outside hypothesis versus outside-inside hypothesis). Th2 and Th17 cytokines have been reported to downregulate filaggrin expression or proper processing of profilaggrin, aggravating the skin barrier perturbation [17] [18]. This creates a vicious circle of inflammation and barrier dysfunction further enhancing allergens, microbes and irritants penetration. Thus, it seems possible that indoor dampness and moulds act as a chronic stimulus topically on the skin causing the appearance and persistence of AD in children. Having in mind that children spend most of their time indoors this perpetuating vicious circle instigate a chronic inflammation independed of atopy.

Dampness and mould is a complex mixture consisting of mites and pets' epithelia, bacterial products, fungi components (mainly Aspergillus spp., Penicillium spp., Cladosporium cladosporioides and Alternaria spp.) and various bio contaminants (pesticides, polycylic aromatic hydrocarbons, polychlorinated biphenyls, alcohols and ketones) [2]. In short, it is a complex of hazardous and beneficial compounds that exceeds far beyond the spectrum of mites and fungi species. It is hard to define the subpopulation of organic components, the concentration of each species, the endotoxin levels or any other non-organic chemical or toxic material contained in it. According to this study, indoor dampness and moulds at least in the context of $\mathrm{AD}$, can act as a reservoir of danger signal molecules that seem to be responsible for the recurrence, relapse and persistence of the skin inflammation.

\section{Limitations}

The present work shares all the methodological limitations of cross-sectional studies, i.e., the lack of causal relationships. Moreover, in ISAAC study the diagnosis of AD was based on two question "Did your child has ever had an itching rash which waxes and wanes for more than 6 months" or "Does your child has had this itching rash the last 12 months”. Thus, diagnosis was based on parents' opinion. Dampness and mould during infancy was also reported by parents memory recalls which may have resulted in bias data record.

\section{Conclusion}

Indoor exposure to dampness and moulds may be considered as a harmful environmental factor not only for the respiratory track but also for the skin. More studies are needed to clarify the contribution of each molecular and the effect of the exposure to different increasing concentrations. Moreover, it is important to evaluate possible interactions between dampness and mould exposure and other environmental factors in both genetically predisposed and naïve children.

\section{References}

[1] Flohr, C. and Mann, J. (2014) New Insights into the Epidemiology of Childhood Atopic Dermatitis. Allergy, 69, 3-16. http://dx.doi.org/10.1111/all.12270

[2] Sousa, A.C., Almeida, J.R., Pereira, C.C., Ramiro Pastorinho, M., Pereira, Â.M., Nogueira, A.J., Taborda-Barata, L., Teixeira, J.P., Correia, A,C. and Alves, A. (2014) Characterization of Fungal Communities in House Dust Samples Collected from Central Portugal-A Preliminary Survey. Journal of Toxicology and Environmental Health, Part A: Current Issues, 77, 972-982. http://dx.doi.org/10.1080/15287394.2014.911137

[3] Piecková, E. and Kunová, Z. (2002) Indoor Fungi and Their Ciliostatic Metabolites. Annals of Agricultural and Environmental Medicine, 9, 59-63.

[4] Park, J.H., Cox-Ganser, J., Rao, C. and Kreiss K. (2006) Fungal and Endotoxin Measurements in Dust Associated with Respiratory Symptoms in a Water Damaged Office Building. Indoor Air, 16, 192-203. 
http://dx.doi.org/10.1111/j.1600-0668.2005.00415.x

[5] Bolte, G., Bischof, W., Borte, M., Lehmann, I., Wichmann, H.E., Heinrich, J., and LISA Study Group (2003) Early Endotoxin Exposure and Atopy Development in infants: Results of a Birth Cohort Study. Clinical \& Experimental Allergy, 33, 770-776. http://dx.doi.org/10.1046/j.1365-2222.2003.01665.x

[6] Gillespie, J., Wickens, K., Siebers, R., Howden-Chapman, P., Town, I., Epton, M., Fitzharris, P., Fishwick, D., Crane, J., and New Zealand Asthma and Allergy Birth Cohort Study Group (2006) Endotoxin Exposure, Wheezing and Rash in Infancy in a New Zealand Birth Cohort. Journal of Allergy and Clinical Immunology, 118, 1265-1270. http://dx.doi.org/10.1016/j.jaci.2006.07.051

[7] Keall, M.D., Crane, J., Baker, M.G., Wickens, K., Howden-Chapman, P. and Cunningham, M. (2012) A Measure for Quantifying the Impact of Housing Quality on Respiratory Health: A Cross-Sectional Study. Environmental Health, 11, 33. http://dx.doi.org/10.1186/1476-069x-11-33

[8] Mendell, M.J., Mirer, A.G., Cheung, K., Tong, M. and Douwes, J. (2011) Respiratory and Allergic Health Effects of Dampness, Mold, and Dampness-Related Agents: A Review of the Epidemiologic Evidence. Environmental Health Perspectives, 119, 748-756. http://dx.doi.org/10.1289/ehp.1002410

[9] Bornehag, C.G., Sundell, J., Hagerhed-Engman, L., Sigsggard, T., Janson, S., Aberg, N., and DBH Study Group (2006) "Dampness" at Home and Its Association with Airway, Nose, and Skin Symptoms among 10,851 Preschool Children in Sweden: A Cross-Sectional Study. Indoor Air, 15, 48-55. http://dx.doi.org/10.1111/j.1600-0668.2005.00306.x

[10] Batlles Garrido, J., Torres-Borrego, J., Bonillo Perales, A., Rubí Ruiz, T., González Jiménez, Y., Momblán De Cabo, J., Aguirre Rodríguez, J., Jiménez Liria, R., Losilla Maldonado, A. and Daza Torres, M. (2010) Prevalence and Factors Linked to Atopic Eczema in 10- and 11-Year-Old Schoolchildren. ISAAC 2 in Almeria, Spain. Allergologia et Immunopathologia, 38, 174-180. http://dx.doi.org/10.1016/j.aller.2009.10.008

[11] Weinmayr, G., Gehring, U., Genuneit, J., B€uchele, G., Kleiner, A., Siebers, R., Wickens, K., Crane, J., Brunekreef, B., Strachan, D.P., and the ISAAC Phase Two Study Group (2013) Dampness and Moulds in Relation to Respiratory and Allergic Symptoms in Children: Results from Phase Two of the International Study of Asthma and Allergies in Childhood (ISAAC Phase Two). Clinical \& Experimental Allergy, 43, 762-774. http://dx.doi.org/10.1111/cea.12107

[12] Thomsen, S.F. (2015) Epidemiology and Natural History of Atopic Diseases. European Clinical Respiratory Journal, 2, 24642. http://dx.doi.org/10.3402/ecri.v2.24642

[13] Ricci, G., Patrizi, A., Baldi, E., Menna, G., Tabanelli, M. and Masi, M. (2006) Long-Term Follow-up of Atopic Dermatitis: Retrospective Analysis of Related Risk Factors and Association with Concomitant Allergic Diseases. Journal of the American Academy of Dermatology, 55, 765-771. http://dx.doi.org/10.1016/j.jaad.2006.04.064

[14] Guo, M.M., Tseng, W.N., Ou, C.Y., Hsu, T.Y., Kuo, H.C. and Yang, K.D. (2015) Predictive Factors of Persistent Infantile Atopic Dermatitis up to 6 Years Old in Taiwan: A Prospective Birth Cohort Study. Allergy, 70, 1477-1484. http://dx.doi.org/10.1111/all.12706

[15] Gavino, A.C., Needham, G.R. and High, W.A. (2008) Atopic Dermatitis, Patch Testing, and House Dust Mites: A Brief Review. Dermatitis, 19, 121-128.

[16] Fuiano, N. and Incorvaia, C. (2012) Dissecting the Causes of Atopic Dermatitis in Children: Less Foods, More Mites. Allergology International, 61, 231-243. http://dx.doi.org/10.2332/allergolint.11-RA-0371

[17] Jacquet, A. (2013) Innate Immune Responses in House Dust Mite Allergy. ISRN Allergy, 2013, Article ID: 735031. http://dx.doi.org/10.1155/2013/735031

[18] Crameri, R., Garbani, M., Rhyner, C. and Huitema, C. (2014) Fungi: The Neglected Allergenic Sources. Allergy, 69, 176-185. http://dx.doi.org/10.1111/all.12325 